\title{
Echinostoma hortense Infection with Enteritis Diagnosed by Upper Gastrointestinal Endoscopy in a Dog
}

\author{
Hiroki OKANISHI ${ }^{1)}$, Jun MATSUMOTO ${ }^{2)}$, Sadao NOGAMI ${ }^{2)}$, Yumiko KAGAWA ${ }^{3)}$ and Toshihiro WATARI ${ }^{1) *}$ \\ ${ }^{1)}$ Laboratory of Comprehensive Veterinary Clinical Studies, Department of Veterinary Medicine, Faculty of Bioresource Sciences, Nihon \\ University, 1866 Kameino, Fujisawa, Kanagawa 252-0880, Japan \\ ${ }^{2)}$ Laboratory of Medical Zoology, Department of Veterinary Medicine, Faculty of Bioresource Sciences, Nihon University, 1866 Kameino, \\ Fujisawa, Kanagawa 252-0880, Japan \\ 3)NORTH LAB Inc., 2-8-35 Kita-hondouri, Shiraishi-ku, Sapporo, Hokkaido 003-0027, Japan
}

(Received 26 November 2012/Accepted 16 February 2013/Published online in J-STAGE 1 March 2013)

ABSTRACT. An 8-year-old male Shiba dog presented with chronic vomiting and diarrhea. Upper gastrointestinal endoscopy revealed severe enteritis and infection of the duodenal mucosa with Echinostoma hortense. We performed therapy for parasites and enteritis. The therapy was successful for deworming and temporarily improved the symptoms, but the dog died soon thereafter. To the authors' knowledge, this is the first case report of an antemortem diagnosis of $E$. hortense infection in a dog.

KEY WORDS: Echinostoma hortense, gastrointestinal endoscopy.

doi: 10.1292/jvms.12-0518; J. Vet. Med. Sci. 75(7): 991-994, 2013

Echinostoma hortense is a member of the Echinostomatidae family, and its characteristics include a large elongated body, a head crown with collar spines and a large oral sucker $[1,5]$. The fluke is zoonotic and inhabits the small intestines of birds and mammals, such as humans and mice [16]. Human echinostomiasis has been identified in China [12], Japan [7, 9] and Korea [16, 18]. Infection with E. hortense was found for the first time after autopsy of a stray dog in an epidemiological study in 1927 [2] and was found again in 1981 [6]. However, antemortem diagnosis and clinical data including those pertaining to therapy for E. hortense infection in dogs have not been described. This report describes a dog with $E$. hortense infection that was diagnosed by upper gastrointestinal endoscopy.

An 8-year-old neutered, domestic, male Shiba dog weighing $6.55 \mathrm{~kg}$ (body condition score, 1) was referred to the Animal Medical Center at Nihon University, Japan. The dog had symptoms of chronic diarrhea, vomiting and weight loss over a period of 4 years. The dog had been kept at the foot of a mountain in Kanagawa, Japan, near a brook and had never been taken outside Japan. At a local animal hospital, the dog received an elimination diet (Sensitivity Control Blue Whiting and Tapioca, Royal Canin, Japan) and antibiotics, but no improvement in symptoms was observed. Prednisolone therapy $(1 \mathrm{mg} / \mathrm{kg} /$ day) temporarily improved excretion from watery diarrhea to loose stool. However, watery diarrhea and vomiting returned soon thereafter, occurring once or twice per week, and the dog was then referred to us. Se-

*Correspondence to: Watari, T., Laboratory of Comprehensive Veterinary Clinical Studies, Department of Veterinary Medicine, Faculty of Bioresource Sciences, Nihon University, $1866 \mathrm{Ka}-$ meino, Fujisawa, Kanagawa 252-0880, Japan.

e-mail: watari@brs.nihon-u.ac.jp

(C)2013 The Japanese Society of Veterinary Science vere weight loss and wambling were evident during the first medical examination, but abdominal tenderness was absent. A blood test revealed (values with reference ranges) albumin (ALB), $1.8 \mathrm{~g} / \mathrm{d} l(2.3-4.0 \mathrm{~g} / \mathrm{d} l)$; total cholesterol (T. chol), 54 $\mathrm{mg} / \mathrm{d} l(110-320 \mathrm{mg} / \mathrm{d} l)$; blood urea nitrogen (BUN), $5 \mathrm{mg} /$ $\mathrm{d} l(7-27 \mathrm{mg} / \mathrm{d} l)$; hematocrit (Ht), 27.5\% (37-55\%); and Creactive protein (CRP), $0.05 \mathrm{mg} / \mathrm{d} l(<1.00 \mathrm{mg} / \mathrm{d} l)$. There was no eosinophilia; the dog had an eosinophil count of $56 / \mu \mathrm{l}$ $(100-1,250 / \mu l)$. No significant abnormalities were observed in a general fecal examination (direct and flotation method), urinalysis, X-ray examination or abdominal ultrasound. Gastrointestinal endoscopy was performed to identify the cause of the anemia, hypoalbuminemia and gastrointestinal symptoms. During gastroduodenal endoscopy, motile flukes were found attached to the edematous duodenal mucosa (Fig. 1). The flukes, which looked slender and elongated, were ex-

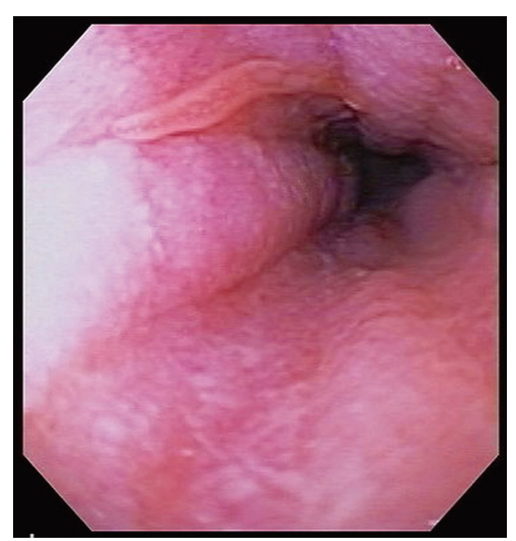

Fig. 1. Endoscopic findings.

A parasitic Echinostoma hortense worm is attached to the duodenal mucosa. 

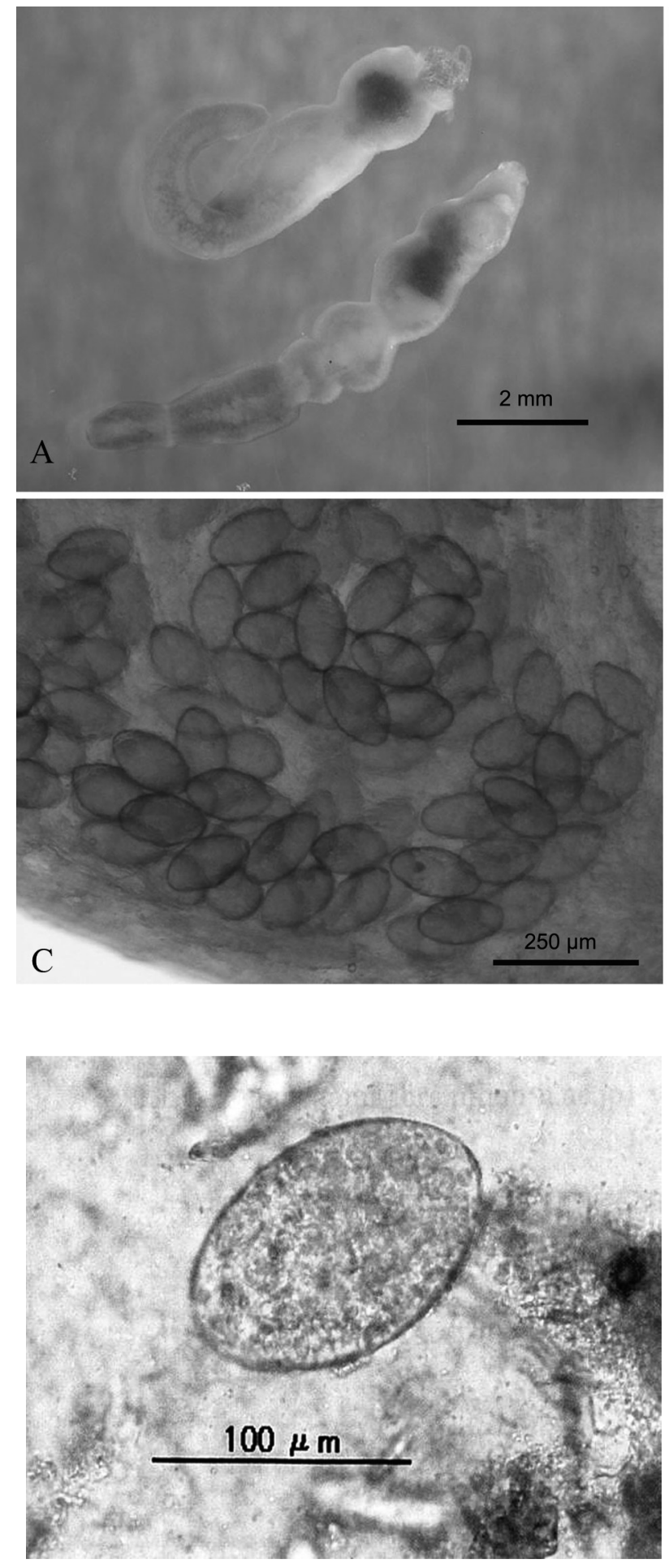

tracted with endoscopic biopsy forceps and transported to the Laboratory of Medical Zoology at Nihon University. They measured approximately $8 \times 1 \mathrm{~mm}$ in size and had a characteristic head crown with 28 collar spines around the subterminal oral sucker. Tandem testes were observed in

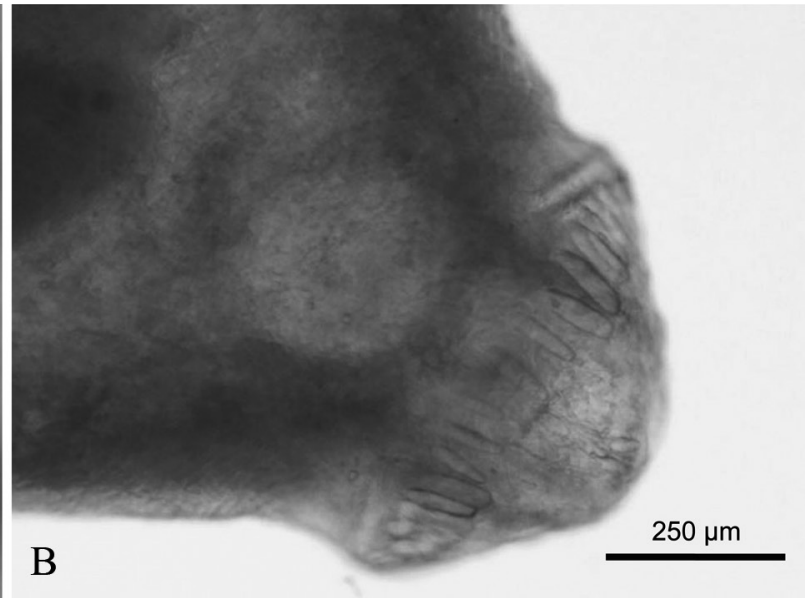

Fig. 2. A; Two flukes obtained using endoscopic biopsy forceps are slender and elongated. B; Features of Echinostoma hortense worms (1). A characteristic head crown of Echinostoma hortense is collared by 28 spines. C; Features of Echinostoma hortense worms (2). The posterior body of Echinostoma hortense has rich vitelline glands.

Fig. 3. Echinostoma hortense egg.

The bright yellow, elliptical, thin-shelled egg has a shallow operculum.

the anterior body, and rich vitelline glands were seen in the posterior body (Fig. 2A, B and C). Stool examination using the formol-ether concentration technique (MGL method) revealed echinostome eggs. The eggs were $120.2 \times 74.1 \mu \mathrm{m}$ in size and were bright yellow, elliptical and thin-shelled with 
a shallow operculum (Fig. 3). The worms were identified as $E$. hortense based on their morphological characteristics and measurements. A histopathological examination of the duodenum revealed severe lymphocytic plasmacytic enteritis (LPE) with lymphangiectasia. The dog was administered 20 $\mathrm{mg} / \mathrm{kg}$ of praziquantel (Droncit; Bayer, Germany) for 3 days to treat the $E$. hortense infection, and the food elimination diet was continued. In addition, the dog was administered a daily antibiotic treatment of $15 \mathrm{mg} / \mathrm{kg} /$ day, b.i.d., metronidazole (Fragyl; Shionogi \& Co., Ltd., Osaka, Japan) and steroid treatment of $1 \mathrm{mg} / \mathrm{kg}$ /day prednisolone (Predonine; Shionogi \& Co., Ltd.) to treat the enteritis, as done at the local animal hospital. Eggs were absent in fecal samples after this therapy. The dog's stool became normal, and vomiting stopped. Blood chemistry parameters also improved somewhat at 33 days after the initial visit (ALB, $2.0 \mathrm{~g} / \mathrm{d} l ; \mathrm{T}$. chol, $91 \mathrm{mg} / \mathrm{d} l$; BUN, $13 \mathrm{mg} / \mathrm{d} l$; Ht, 34\%; CRP, $0.25 \mathrm{mg} / \mathrm{d} l$ ). However, weight loss, diarrhea and increased CRP levels (11 $\mathrm{mg} / \mathrm{d} l$ ) were observed at 83 days after initial presentation. Fecal examinations were again performed using the MGL method, but eggs were not found. Endoscopy of the duodenum and colon was then performed. Edema, erosion and flare were observed in the intestinal mucosa, but no flukes were found. Histopathological findings indicated severe LPE in the duodenum and mild inflammation in the colon. The steroid dose was increased to $2 \mathrm{mg} / \mathrm{kg} / \mathrm{day}$, and $5 \mathrm{mg} / \mathrm{kg} /$ day cyclosporine (Neoral; Novartis, NY, U.S.A.) and $10 \mathrm{mg} / \mathrm{kg} /$ day b.i.d. mesalazine (Pentasa; Kyorin Pharmaceutical Co., Ltd.., Tokyo, Japan) were added to treat the chronic enteritis. However, the dog died following additional weight loss and exacerbated diarrhea at 171 days after the initial referral.

Epidemiological investigations in Japan have identified $E$. hortense infection in 4.9\% (26/531) and 4.6\% (4/87) of feral raccoons (Procyon lotor) collected from Wakayama and Shimane, respectively [10, 17]. Furthermore, E. hortense infection has been detected in 19.2\% (10/52) and 5.2\% (1/19) of Ezo red foxes (Vulpes vulpes schrencki) in Hokkaido and American mink (Mustela vison) in Nagano, respectively [11, 13]. There are no reports in dogs and cats; however, these previous findings indicate that the risk of $E$. hortense infection is quite prevalent in Japan. There are 54 reported cases of infection in humans, mostly in Akita $(n=18)$, Okayama $(n=14)$ and Osaka $(n=7)$ [19]. All cases of infection in humans developed after consuming fish, such as loach in local dishes. Humans become infected with E. hortense mainly through the ingestion of raw freshwater fish or raw loach [5, 20]; one woman became infected after ingesting fresh water from a reservoir [20]. The route of infection in the Shiba dog described herein remains unknown, as it was fed a diet comprising only dry dog food. However, the dog could have ingested a secondary intermediate host or metacercaria from the brook located near where the dog lived.

The dog presented with anorexia, vomiting and diarrhea. These symptoms might have been due to mucosal irritation caused by E. hortense, as they disappeared temporarily after deworming. The hypoalbuminemia, hypocholesterolemia, low BUN and moderate anemia might have been caused by malabsorption and enteritis of the intestinal mucosa due to the infection. The small intestine, particularly the duodenum, is the usual site of $E$. hortense infection in humans [3, $4,8]$. In the present case, the parasites were also found in the duodenum by endoscopy. However, as the jejunum and ileum were not investigated by endoscopy or autopsy, the parasitic status in these regions remains unknown.

Detailed observation of flukes in humans has been reported using indigo carmine staining [20]. In the present case, worms could be found by endoscopy without the use of indigo carmine staining. Eggs can be difficult to find by direct and flotation methods of fecal examination. In fact, fecal examinations at a local animal hospital and at our hospital did not identify any eggs. However, we identified E. hortense eggs using the MGL method, which is not the standard stool examination used in clinical practice. This method should be aggressively applied in animal hospitals. Praziquantel is generally recommended as an antiparasitic drug for the treatment of $E$. hortense in humans [5, 20] at doses ranging from 20 to $75 \mathrm{mg} / \mathrm{kg}$ for 1 to 3 days [7, 9, 19], but doses for dogs have not been established. This therapy eradicated flukes and eggs in the dog described herein and stopped the diarrhea and vomiting. However, enteritis worsened, eventually causing death. The enteritis might have been caused by a gastrointestinal disease other than parasitic infection. Shiba dogs with chronic enteropathy have a poor prognosis [14, 15]. Furthermore, a neoplastic disease, such as lymphoma, might also have been a cause of death. The precise cause of death in this dog remains unknown, because we could not perform an autopsy.

In summary, this is the first report of E. hortense infection diagnosed using endoscopy in a live dog. Our treatment strategy was as successful as in humans, and the dog's symptoms temporarily improved, although it subsequently died. Further studies of more cases are needed to clarify the effects of $E$. hortense infection in dogs.

\section{REFERENCES}

1. Arizono, N., Uemoto, K., Kondo, K., Matsuno, K. and Yoshida, Y. 1976. Studies on Echinostoma hortense Asada, 1926 with special reference to its human infection. Jpn. J. Parasitol. 25: 36-45 (in Japanese).

2. Asada, J. 1927. A new trematode found in a dog of vicinity of Tokyo city. Tokyo Ijishinshi 2522: 926-930 (in Japanese).

3. Chai, J. Y., Hong, S. T., Lee, S. H., Lee, G. C. and Min, Y. I. 1994. A case of echinostomiasis with ulcerative lesions in the duodenum. Korean. J. Parasitol. 32: 201-204. [Medline] [CrossRef]

4. Chang, Y. D., Sohn, W. M., Ryu, J. H., Kang, S. Y. and Hong, S. J. 2005. A human infection of Echinostoma hortense in double bulb diagnosed by endoscopy. Korean. J. Parasitol. 43: 57-60. [Medline] [CrossRef]

5. Cho, C. M., Tak, W. Y., Kweon, Y. O., Kim, S. K., Choi, Y. H., Kong, H. H. and Chung, D. I. 2003. A human case of Echinostoma hortense (Trematoda: Echinostomatidae) infection diagnosed by gastroduodenal endoscopy in Korea. Korean. $J$. Parasitol. 41: 117-120. [Medline] [CrossRef]

6. Cho, S. Y., Kang, S. Y. and Ryang, Y. S. 1981. Helminthes infections in the small intestine of stray dogs in Ejungbu city, Kyunggi do, Korea. Korean. J. Parasitol. 19: 55-59. [Medline] 
[CrossRef]

7. Hamamoto, T., Kawasaki, H., Maejima, J. and Hirai, K. 1997. A case of Echinostoma hortense infection diagnosed by the upper gastrointestinal endoscopy. J. Gastroenterol. 94: 487-491. [Medline]

8. Harada, H., Fukumoto, K., Yamaguchi, K., Kondo, M., Yoshida, Y., Shiota, T., Yamada, M., Furukawa, K., Tada, M. and Akamatsu, H. 1983. Echinostoma hortense infection diagnosed by the endoscopical examination. Gastroenterological Endoscopy 25: 622-627.

9. Haruma, K. 2007. A human case of Echinostomiasis. pp. 5-7. In: GI Forefront, vol. 3, no. 2, Medical review, Osaka (in Japanese).

10. Kanamori, H., Takeshita, Y., Sawada, S. and Kanazawa, N. 2012. The present status of feral raccoons in Shimane prefecture, Japan. Bull.Shimane Pref. Mount. Reg. Res. Ctr. 8: 51-62 (in Japanese).

11. Kumakawa, S. 2005. Fish-eating American minks (Mustera vison) in the upstream site of Chikumagawa-river. p. 44. In: A Business report of the Nagano Prefectural Fisheries Experiment Station (2005) (in Japanese).

12. Liu, X. Q. and Shi, H. H. 2011. Two cases infected by Echinostoma hortense in Guangxi. Chinese. J. Parasitol. Parasitic Dis. 29: 77.

13. Morishima, Y., Tsukada, H., Matsuo, K., Shimizu, M., Nikaidou, R., Nonaka, N., Oku, Y. and Kamiya, M. 1998. The survey of intestinal helminthes in red foxes in the urban area of Sapporo and Shiretoko (an interim report). 1998. The 45th Annual Meeting of the Japanese Society of Parasitology (a Branch of Northern Japan) 2nd Sess.
14. Ohmi, A., Ohno, K., Uchida, K., Nakayama, H., Koshino-Goto, Y., Fukushima, K., Takahashi, M., Nakashima, K., Fujino, Y. and Tsujimoto, H. 2011. A retrospective study in 21 Shiba dogs with chronic enteropathy. J. Vet. Med. Sci. 73: 1-5. [Medline] [CrossRef]

15. Ohno, K., Konishi, S., Kobayashi, S., Nakashima, K., Setoguchi, A., Fujino, Y., Nakayama, H. and Tsujimoto, H. 2006. Prognostic factors associated with survival in dogs with lymphocyticplasmacytic enteritis. J. Vet. Med. Sci. 68: 929-933. [Medline] [CrossRef]

16. Ryang, Y. S., Ahn, Y. K., Lee, K. W., Kim, T. S. and Han, M. H. 1985. Two cases of natural human infection by Echinostoma hortense and its second intermediate host in Wonju area. Korean J. Parasitol. 23: 33-40. [Medline] [CrossRef]

17. Sato, H. and Suzuki, K. 2006. Gastrointestinal helminthes of feral raccoons (procyon lotor) in Wakayama prefecture, Japan. J. Vet. Med. Sci. 68: 311-318. [Medline] [CrossRef]

18. Seo, B. S., Hong, S. T., Chai, J. Y. and Lee, S. H. 1983. Studies on intestinal trematodes in Korea VIII. A human case of Echinostoma hortense infection. Korean. J. Parasitol. 21: 219-223. [Medline] [CrossRef]

19. Shiota, K. 1989. Echinostomiasis. pp. 851-855. In: Saishinigaku, vol. 44, Saishinigaku, Osaka (in Japanese).

20. Tanaka, T., Komada, T., Koga, H., Tanaka, A., Manabe, N., Hata, J., Kusunoki, H., Ishii, M., Sato, M., Tarumi, K., Siotani, A., Okino, T. and Haruma, K. 2008. Echinostoma hortense Asada infection in the duodenum: incidental findings during findings during routine gastrointestinal endoscopy. Digestive Endoscopy 20: 87-89. [CrossRef] 